\title{
Euflammation attenuates central and peripheral inflammation and cognitive consequences of an immune challenge after tumor development
}

\author{
Savannah R. Bever ${ }^{1,2}$, Xiaoyu Liu ${ }^{1,3}$, Ning Quan ${ }^{1,3}$, and Leah M. Pyter ${ }^{*}, 1,2,4,5,6$ \\ ${ }^{1}$ Institute for Behavioral Medicine Research, Ohio State University Wexner Medical Center, \\ Columbus, $\mathrm{OH}$, USA \\ ${ }^{2}$ Department of Psychiatry and Behavioral Health, Ohio State University Wexner Medical Center, \\ Columbus, $\mathrm{OH}$, USA \\ ${ }^{3}$ Division of Biosciences, Ohio State University, Columbus, $\mathrm{OH}$, USA \\ ${ }^{4}$ Department of Neuroscience, Ohio State University Wexner Medical Center, Columbus, $\mathrm{OH}$, \\ USA \\ ${ }^{5}$ Behavioral Neuroendocrinology Group, Ohio State University, Columbus, OH, USA \\ ${ }^{6}$ Arthur G. James Comprehensive Cancer Center and Solove Research Institute, Ohio State \\ University, Columbus, OH USA
}

\begin{abstract}
Objective-Repeated subthreshold bacterial exposures in rodents cause novel euflammation that attenuates neuroinflammation and sickness behaviors upon subsequent infectious challenges to the host without eliciting illness behavior. The investigation of bacterial exposure effects on brain and behavior is clinically-relevant because bacterial-based antitumor treatments are used successfully, but are suboptimal due to their illness side effects. In addition, behavioral consequences (depression, cognitive impairments) to homeostatic challenges that are associated with inflammation are prevalent and reduce quality of life in cancer patients and survivors. Therefore, this study tested the potential for euflammation to attenuate behavioral consequences of an immune challenge in tumor-bearing mice.
\end{abstract}

Methods-Mice with and without oral tumors in their flank received the established peripheral euflammatory protocol or vehicle, followed by an acute peripheral immune challenge (lipopolysaccharide [LPS] injection) or saline. Cognitive function and sickness behavior was assessed after the challenge and peripheral and central inflammatory responses were measured.

Results-Euflammation reduced LPS-induced peripheral and central inflammation in all mice, however neuroinflammation was less attenuated in tumor-bearing mice compared with tumor-free *Corresponding author: Leah M. Pyter, Ohio State University, 219 Institute for Behavioral Medicine Research, 460 Medical Center Dr,
Columbus OH 43210, t. 614.293.3496, f. 614.366.2097, leah.pyter@ osumc.edu.

CONFLICT OF INTEREST: The authors have no conflicts of interest to declare.

ETHICS STATEMENT: All experiments were approved by the Ohio State University Institutional Animal Care and Use Committees and carried out in accordance with the National Institutes of Health Guide for the Care and Use of Laboratory Animals. 
controls. LPS-induced lethargy and cognitive impairments were more pronounced among tumorbearing mice and were effectively attenuated with euflammation. Cognitive changes were independent of brain-derived growth factor gene expression in the hippocampus.

Conclusion-These results suggest that induction of euflammation may be useful in alleviating the negative side effects of bacterial-based tumor treatments and in potentially attenuating common behavioral comorbidities associated with cancer or other chronic diseases.

\section{Keywords}

cancer; lipopolysaccharide; cytokines; neuroinflammation; behavior; BDNF

\section{INTRODUCTION}

Activation of the peripheral innate immune system above a threshold initiates inflammatory signaling to the brain resulting in neuroinflammation and sickness behavior in rodents (lethargy, fever, hyperalgesia, anorexia) [1]. However, repeated, incrementally increased subthreshold infectious stimuli in the periphery (e.g., Escherichia coli) attenuate circulating cytokines, neuroinflammatory, and sickness behavior responses to subsequent immune challenges [2,3]. Notably, this novel "euflammatory" protocol diverges from endotoxin or LPS tolerance/conditioning in that euflammation does not induce sickness behavior during the conditioning phase. Currently, repeated low-dose injections of other types of bacteria (e.g., Salmonella, Clostridium [4]) are used to effectively reduce tumor mass and prolong survival in cancer patients by activating anti-cancer immunity or as tumor-targeting vehicles [5,6]. Indeed, treatment of oral cancer in this manner has mounting potential [7]. However, this treatment occasionally causes significant illness behavior in cancer patients, thereby causing premature termination of the treatment [8]. Therefore, the application of a euflammation protocol may ameliorate treatment discontinuation due to negative side effects.

Cancer patients and survivors exhibit mild to moderate cognitive impairments compared with cancer-naïve controls [9]. These cognitive impairments can persist as much as 20 years after cancer treatment [10] and significantly reduce quality of life [11] and employability [12]. While cancer treatments and stress contribute to mental health issues associated with cancer, pretreatment clinical findings and tumor models indicate that tumor biology also plays a significant role $[13,14]$. Cognitive issues are documented in the oral cancer population specifically $[15,16]$, even prior to cancer treatments (chemotherapy, radiation) [17], indicating a causal role of tumor biology alone. Cognitive decline in cancer patients is detrimental to overall long-term quality-of-life. Furthermore, behavioral responses to homeostatic challenges (e.g., stressors) unmask additional behavioral difficulties [14]. For example, following a cold temperature stressor challenge, breast cancer patients and survivors had greater difficulty recalling narrative information and lacked the stress-induced benefits to emotional memory recall compared with cancer-free controls [18]. Likewise, abdominal surgery (i.e., an immune stressor) elicits a greater circulating proinflammatory cytokine response among colon cancer patients compared to cancer-free controls [19]. Thus, a prior cancer experience alters immune responses to challenges. Therefore, in addition to the potential improvements in side effects caused by antitumor bacterial treatments, 
euflammation may also ameliorate exaggerated brain and immune consequences to inevitable immune challenges experienced by cancer patients (e.g., viral infection, surgery).

Rodent models of cancer demonstrate that tumors are sufficient to induce cognitive impairments and neuroinflammation [20,21]. In one rodent model of breast cancer, neuroinflammatory responses to an acute, peripheral bacterial mimetic (lipopolysaccharide) were elevated among tumor-bearing rats relative to tumor-free controls [22]. Taken together, these studies suggest that inflammatory responses to immune challenges may be altered by cancer and contribute to cancer-associated behavioral comorbidities.

This study was designed to test the effectiveness of an established euflammation protocol $[2,3]$ in reducing central and peripheral inflammation and cognitive consequences of an immune challenge after tumor development. Specifically, this work focuses on modulation of the euflammatory network by a peripheral tumor. In addition, the extent to which euflammation modulates post-LPS behavior was extended from sickness behaviors to cognition and the positively associated brain-derived growth factor [23]. Finally, the inverse relationship, that euflammation may influence tumor growth was also tested.

\section{MATERIALS AND METHODS}

\subsection{Animals}

Male 7- to 8-week old endotoxin-sensitive [24] C3H/HeNCrl mice (Charles River, Wilmington, MA) were housed 3/cage and acclimated to the temperature-controlled (22 $\pm 1{ }^{\circ} \mathrm{C}$ ) vivarium for 1 week under a 12:12 light:dark cycle (lights on at 06:00 h EST). Rodent chow (Harlan 7912) and water were available ad libitum throughout the study and cotton nestlets were provided for nest building. All mice were acclimated to handling twice weekly prior to experimental procedures. All experiments were approved by the Ohio State University Institutional Animal Care and Use Committees and carried out in accordance with the National Institutes of Health Guide for the Care and Use of Laboratory Animals [25]. All efforts were made to minimize animal suffering and to reduce the number of mice used. Forty-eight mice were used for Experiment 1 and thirty were used for Experiment 2.

\subsection{Cells}

The murine oral cancer cell line AT-84, originating from a spontaneous oral tumor in $\mathrm{C} 3 \mathrm{H}$ mice, was generously provided by Dr. Shulin Li at MD Anderson (Houston, TX, USA). Cells were grown in RPMI-1640 with 10\% FBS, 2 mM L-glutamine, $0.1 \mathrm{mM}$ non-essential amino acids, $10 \mathrm{mM} \mathrm{N}$-2-HEPES buffer, 100 units penicillin/ml, and $100 \mu \mathrm{g}$ streptomycin/ml at $37{ }^{\circ} \mathrm{C}$ with $5 \% \mathrm{CO}_{2}[26]$.

\subsection{Experimental Design}

Effects of tumors on euflammation: Experiment 1-Between 8-9 weeks of age, half of the mice were inoculated with tumor cells ( $\mathrm{n}=24$; "Tumor") or PBS vehicle ( $\mathrm{n}=24$; "No Tumor"). Two and a half weeks after tumor induction, when tumor sizes were approximately $500 \mathrm{~mm}^{3}$, subsets of the mice received the 3-day euflammation protocol ("Euflamm") or the control protocol ("No Euflamm") followed the next day by an acute inflammatory challenge 
or control. One and a half hours after the inflammatory challenge, cognitive function was assessed in all mice (1.5-5.5 h after challenge) followed immediately by tissue collection (5.5 $\mathrm{h}$ after challenge). Mice were psuedorandomly ordered by treatment to eliminate potential temporal biases. Blood, hippocampus, hypothalamus, frontal cortex, spleen, and tumors were collected for this experiment. One mouse from the tumor group died spontaneously and was removed from the study; another mouse in the tumor group was removed because the tumor was $<125 \mathrm{~mm}^{3}$. See Figure $1 \mathrm{~A}$ for the experimental timeline and sample sizes.

Effects of euflammation on tumor growth: Experiment 2-Between 8-9 weeks of age, two-thirds of the mice received the 3-day euflammation protocol $(n=20)$ and the other third received the control treatment $(n=10)$. The next day, all mice were inoculated with either tumor cells or PBS vehicle. An acute inflammatory challenge or control injection occurred $23 \mathrm{~d}$ later, when tumors were approximately $800 \mathrm{~mm}^{3}$. The hippocampus, hypothalamus, and tumors were collected for this experiment. See Figure 1B for the experimental timeline and sample sizes.

\subsection{Tumor Induction}

Mice were first anesthetized (isoflurane inhalant) and then injected in the flank (s.c.) with either $50 \mu \mathrm{l}$ of a suspension of $1.5 \times 10^{6}$ AT- 84 cells or PBS vehicle [26]. Ear notches were made at this time for identification purposes. This procedure results in non-metastatic oral squamous cell carcinomas [27], the most common type of oral cancer in humans. This is a validated syngeneic model, permitting the use of mice with intact immune systems [28]. Body mass and tumor volume were measured twice/week. The longest diameter of the tumor (A) and the perpendicular diameter (B) were used to estimate tumor volume by the formula: $\mathrm{V}=\mathrm{A} \times \mathrm{B}^{2} / 2 \mathrm{~mm}^{3}$.

\subsection{Euflammation}

The euflammation protocol was previously described [2]. Briefly, the euflammatory protocol consisted of three increasing, consecutive daily injections of E. coli (strain LT004; i.p.): $2 \times$ $10^{7}$ CFUs on day $1,25 \times 10^{7}$ CFUs on day 2, and $100 \times 10^{7}$ CFUs on day 3. E. coli was suspended in $100 \mu \mathrm{l}$ sterile PBS for injection. Mice without euflammation received $100 \mu \mathrm{l}$ i.p. injections of PBS at the same time.

\subsection{Acute inflammation induction}

One day after the euflammation protocol (9:00 h EST, mice were injected i.p. with bacterial lipopolysaccharide (LPS; E. coli 0111:B4, $250 \mu \mathrm{g} / \mathrm{kg}$ ) or $100 \mu \mathrm{l}$ of sterile PBS.

\subsection{Tests of cognitive abilities}

Spontaneous alternation-This spatial working memory test was performed based on a modified version of a previously described procedure [29]. A Y-maze, consisting of 3 equallength gray acrylic arms $(40 \mathrm{~L} \times 8 \mathrm{~W} \times 15 \mathrm{H} \mathrm{cm})$ at $120^{\circ}$ angles from each other, was used. Mice were placed initially in the center (10:30 h EST) and allowed to explore the entire maze for $3 \mathrm{~min}$. This test is based on the natural tendency of rodents to methodically explore 
relatively novel arms rather than the most recently explored arms. The series of arm entries was recorded using an overhead camera and tracked using ANY-Maze video tracking software (Stoelting Co., San Diego, CA, USA). A successful alternation was defined as successive entries into each of the three arms in any order. Percent spontaneous alternation was calculated as the ratio of successful alternations over total possible alternations (defined as the total number of arm entries minus two) and multiplied by 100 .

Novel object recognition-This non-spatial cognitive task is mediated by the temporal cortex and is based on rodents' preference to investigate novel versus familiar objects. This task was performed as previously described [15]. Briefly, after completing the spontaneous alternation test, mice were allowed to investigate 2 identical objects (upright $50 \mathrm{ml}$ conical tubes filled with sand) for $10 \mathrm{~min}$ in a clean cage, after which they were returned to their homecage. Three hours later, mice were returned to the clean cage, but one familiar object was replaced with a novel object (hockey puck). Relevant to mouse strains prone to retinal degeneration such as $\mathrm{C} 3 \mathrm{H}$, visual input is not required for novel object recognition when objects differ by various sensory modalities (size, shape, color, material, texture) [30] and has been used successfully in this strain [30-32]. Investigative behavior was scored for 5 min. All objects were rinsed with $70 \%$ ethanol between trials. Videos were scored using Etholog v. 2.2 freeware (Sao Paulo, Brazil). Investigation was defined as object-directed behavior with the nose $<1 \mathrm{~cm}$ from an object and vibrissae moving. A novel object discrimination index (DI) was calculated: (Time spent investigating novel object - Time spent investigating familiar object)/(Total time spent investigating either object) $\times 100$.

\subsection{Tissue collection}

Following rapid decapitation, trunk blood was collected in heparin-lined blood collecting tubes (14:30 h EST). Blood was used to measure circulating cytokine concentrations. The brains were removed and the hypothalamus was dissected and flash frozen, the rest of the brain was bisected and stored in RNA Later for later dissection of the hippocampus and frontal cortex. All samples were frozen at $-80{ }^{\circ} \mathrm{C}$ until neuroinflammatory gene expression assessment. Tumors and spleens were removed and weighed.

\subsection{Plasma cytokine concentrations}

To compare circulating inflammatory responses among treatments, interleukin (IL)-1 $\beta$, IL-6, keratinocyte chemoattractant (CXCL1), and tumor necrosis factor (TNFa) were measured in plasma samples in duplicate using a multiplex fluorescent bead array (Mouse Inflammatory V-Plex Panel; Mesoscale Discovery, Rockville, MD, USA) according the manufacturer's protocol. Detection thresholds were $0.11,0.61,0.24$, and $0.13 \mathrm{pg} / \mathrm{ml}$, respectively. All samples were detectable for all cytokines. Intrassay and interassay variations were each $<10 \%$.

\subsection{Quantitative RT-PCR}

Total RNA was extracted from the individual brain regions collected using Qiagen RNeasy mini kits (CA, USA). RNA concentrations were measured and 260/280 ratios were determined to be 1.8-2.0 (NanoDrop, DE, USA). Total RNA was reverse transcribed using SuperScript First-Strand kits (Invitrogen, NY, USA) according to the manufacturer's 
protocol. Four genes of interest were chosen based on their established role in neuroinflammation-induced cognitive behavioral effects (II1b, Il6, Tnfa, Cd11b; Kim et al., 2016). Bdnf gene expression was examined in the hippocampus based on its role in promoting cognition through neuronal health and proliferation [34]. Mouse TaqMan gene expression assays were purchased from Applied Biosystems (Carlsbad, CA, USA) with probes labeled with 6-FAM and MGB (non-fluorescent quencher) at the $5^{\prime}$ and $3^{\prime}$ ends, respectively: Il-1b(Mm00434228_m1), Il-6(Mm00446190_m1), Tnfa (Mm00443258_m1), Cd11b (Mm00434455_m1), Bdnf (Mm04230607_s1), and (Gapdh (Mm99999915_g1; labeled with VIC). The universal single-plex two-step RT-PCR cycling conditions used on the 7900HT Sequence Detection System (Applied Biosystems) were: $50{ }^{\circ} \mathrm{C}(2 \mathrm{~min}), 95{ }^{\circ} \mathrm{C}$ (10 min), 40 cycles of $95^{\circ} \mathrm{C}(15 \mathrm{~s})$ and $60{ }^{\circ} \mathrm{C}(1 \mathrm{~min})$. Relative gene expression of individual samples run in duplicate was calculated by the comparative $\mathrm{C}_{\mathrm{T}}$ method $\left(2^{-\Delta \mathrm{CT}}\right)$.

\subsection{Statistical analysis}

Statistical comparisons of tissue mass, protein and gene expression, and behavior were analyzed using 2-way ANOVAs followed by post-hoc Fisher's LSD or Student's $t$-tests based on a priori hypotheses with Statview version 5.0.1 software (Scientific Computing, Cary, NC, USA) when variance was normal. Nonparametric Mann-Whitney $U$ tests were used when variance was not normally distributed. Repeated measures ANOVAs were used to compare changes in body mass over time. Data were determined to be statistically significant when $p \unlhd 0.05$ and are presented as mean \pm standard error of the mean (SEM).

\section{RESULTS}

\section{Experiment 1: Effects of tumors on euflammation}

3.1 Tissue masses-All mice gained weight over the three weeks of tumor growth prior to the euflammation treatment (Figure $2 \mathrm{~A} ; F_{3,135}=110.8, p<0.0001$ ); tumor growth did not affect body mass $(p>0.05)$. The three-day euflammation protocol ("Euflamm Day 1" through "Pre-LPS") interacted with time to affect body mass (Figure $2 \mathrm{~B} ; F_{1,43}=5.2, p<0.05$ ), such that mice without euflammation gained weight over this time period, whereas those that received euflammation did not. Body weight changed over the 4-h post-LPS treatment period (Figure $2 \mathrm{~B} ; F_{1,38}=56.8, p<0.0001$ ), driven primarily by a tendency for weight loss in all LPS-treated mice $(F 1,38=3.5, p=0.07)$.

Neither euflammation nor LPS treatments influenced final tumor mass (Figure $2 \mathrm{C} ; p>0.05$ ). Both euflammation $\left(F_{1,39}=16.0 ; p<0.001\right)$ and LPS treatment $\left(F_{1,39}=7.9 ; p<0.01\right)$ independently increased spleen mass, whereas tumors did not (Figure $2 \mathrm{D} ; p>0.05$ ). The LPS-induced increase in spleen weight appeared to be driven by all pairwise comparisons, except for the tumor-free euflammation group $(p>0.05)$.

3.2 Circulating cytokines-Both euflammation and LPS treatments, independently altered circulating IL-1 $\beta$ (Figure $3 \mathrm{~A} ; F_{1,31} 17.6 ; p<0.001, F_{1,31}=36.3 ; p<0.0001$ ), IL-6 (Figure 3B; $F_{1,33}=11.6, p<0.01 ; F_{1,33}=13.1, p<0.01$ ), CXCL1 (Figure 3C; $F_{1,31}=31.0$, $p<0.0001 ; F_{1,31}=38.0, p<0.0001$ ), and TNFa (Figure 3D; $F_{1,30}=14.5, p<0.001 ; F_{1,30}=28.8$, $p<0.0001$ ) concentrations, as well as their interaction (IL-1 $\beta: F_{1,31}=17.9, p<0.001$; IL-6: 
$F_{1,33}=11.5 ; p<0.01$; CXCL1: $F_{1,31}=29.6, p<0.0001$; TNFa: $\left.F_{1,30}=15.4, p<0.001\right)$. Thus, euflammation reduced LPS-induced increases in all four cytokines in both tumor-free (IL-1 $\beta: t_{8}=7.8, p<0.0001$;L-6: $t_{10}=3.6, p<0.01$; CXCL1: $t_{10}=2.8,{ }_{\mathrm{p}}<0.05$; TNFa: $t 10=2.3$, $p<0.05$ ) and tumor-bearing (IL-1 $\beta: t_{10}=2.3, p<0.05$; IL-6: $t_{10}=3.0, p<0.05$; CXCL1: $t 8=48.1$, $p<0.0001$; TNFa: $\left.t_{8}=4.1, p<0.01\right)$ mice relative to their respective non-euflammation controls. Tumor treatment did not independently influence the overall ANOVAs ( $p>0.05$ in all cases). However, tumors tended to attenuate these euflammation-induced reductions in IL- $1 \beta$ after LPS relative to tumor-free controls (Figure $3 \mathrm{~A} ; U=7 ; p=0.08$ ). This attenuation was not observed in the other circulating cytokines ( $p>0.05$ in all cases). Tumors also tended to increase LPS-induced TNFa among mice without euflammation (Figure 3D; $t_{10}=2.0$; $p=0.08)$. All PBS-treated mice had comparable IL-1 $\beta$, IL-6, and TNFa regardless of euflammation and tumor treatments ( $p>0.05)$. Euflammation decreased CXCL1 among all PBS-treated mice (Figure $3 C ; F_{1,13}=5.3, p<0.05$ ), which was driven primarily by the trend within tumor-bearing mice $\left(t_{6}=1.7, p=0.1\right)$.

\subsection{Neuroinflammation}

II1ß: Both euflammation and LPS treatment, independently altered hippocampal III $\beta$ (Figure 4A; $F_{1,35}=8.7, p<0.01, F_{1,35}=33.3, p<0.0001$ ) as well as their interaction $\left(F_{1,35}=12.3, p<0.005\right)$, such that euflammation attenuated LPS-induced increases in $I 11 \beta$ mRNA expression in both tumor-free $\left(t_{8}=2.7, p<0.05\right)$ and tumor-bearing mice ( $U=2$, $p<0.05$ ). In the overall ANOVA, LPS treatment significantly increased hypothalamic (Figure $4 \mathrm{~B} ; F_{1,38}=34.5, p<0.0001$ ) and frontal cortex (Figure 4C; $\left.F_{1,37}=27.3, p<0.0001\right) I 11 \beta$. However, relative to PBS-controls, LPS failed to significantly increase $I I 1 \beta$ after euflammation in the hippocampus and in the frontal cortex of LPS-treated tumor-bearing mice. Euflammation only attenuated LPS-induced $I 11 \beta$ increases in tumor-free mice relative to no euflammation controls in the frontal cortex (Figure $4 \mathrm{C} ; U=4, p<0.05$ ). In this brain region, the interactions between euflammation and LPS treatment $\left(F_{1,37}=4.3, p<0.05\right)$ and between euflammation and tumor treatment $\left(F_{1,37}=5.4, p<0.05\right)$ were statistically significant. Within the PBS-treated mice, euflammation increased hypothalamic $I 11 \beta$ mRNA (Figure 4B; $F_{1,19}=6.1, p<0.05$ ), although pairwise comparisons within the tumor treatments were not significantly different ( $p>0.05$ in both cases). PBS-treated mice were not affected by euflammation treatment in the hippocampus or frontal cortex for this gene.

I6: Both euflammation and LPS treatment independently altered hippocampal, hypothalamic, and frontal cortex $I 16 \mathrm{mRNA}$ (Figure 4D-F) (hippocampal: $F_{1,36}=31.1$, $p<0.0001 ; F_{1,36}=34.1, p<0.0001$; hypothalamic: $F_{1,38}=17.3, p<0.0005 ; F_{1,38}=22.7$, $p<0.0001$, frontal cortex: $\left.F_{1,37}=17.5, p<0.0005, F_{1,37}=17.4, p<0.0005\right)$ as well as their interaction (hippocampal: $F_{1,36}=32.7, p<0.0001$; hypothalamic: $F_{1,38}=21.3, p<0.0001$; frontal cortex: $\left.F_{1,37}=18.4, p<0.0005\right)$. Thus, euflammation reduced LPS-induced increases in $I 16 \mathrm{mRNA}$ compared to no euflammation, regardless of tumor treatment ( $U=0, p<0.01$ in all cases). Conversely, LPS increased brain $116 \mathrm{mRNA}$ in all mice without euflammation ( $U=0, p<0.01$ in all cases) relative to PBS controls, regardless of tumor treatment. PBStreated mice were not affected by euflammation or tumor treatments in any brain region examined for this gene $(p>0.05)$. Tumors did not significantly alter responses of this gene $(p>0.05)$. 
Tnfa: Both euflammation and LPS treatment, independently altered hippocampal and frontal cortex Tnfa mRNA (Figure 4G,I) (hippocampal: $F_{1,36}=6.4, p<0.05 ; F_{1,36}=18.4$, $p<0.0005$; frontal cortex: $\left.F_{1,37}=19.1, p<0.0001 ; F_{1,37}=72.6, p<0.0001\right)$ as well as their interaction (hippocampal: $F_{1,36}=8.9, p<0.01$; frontal cortex: $F_{1,37}=22.6, p<0.0001$ ). Thus, euflammation attenuated LPS-induced increases in Tnfa relative to no euflammation for both tumor-free (hippocampal: $t_{8}=3.1, p<0.05$, frontal cortex: $t_{9}=3.4, p<0.01$ ) and tumor bearing (hippocampal: $U=0, p<0.01$; frontal cortex: $t_{9}=3.4, p<0.01$ ) mice in these two brain regions. LPS failed to significantly increase Tnfa in the tumor-free mice ( $p>0.05$ in both regions), but not the tumor-bearing mice (hippocampal: $t_{10}=3.3, p<0.01$; frontal cortex: $t_{10}=5.6, p<0.005$ ), relative to their PBS controls. This was reflected in the overall ANOVA for frontal cortex by both the interaction between tumors and euflammation and tumors, euflammation, and LPS treatments approaching statistical significance $\left(F_{1,37}=2.8, p=0.1\right.$, $F_{1,37}=2.9, p=0.1$ ). In the overall ANOVA for the hypothalamus (Figure $4 \mathrm{H}$ ), only LPS treatment independently increased $\operatorname{Tnf} a\left(F_{1,37}=75.1, p<0.0001\right)$, although the interaction between euflammation and LPS treatments was also statistically significant $\left(F_{1,37}=6.2\right.$, $p<0.05)$. Thus, LPS increased hypothalamic Tnfa in all mice relative to PBS-treated controls ( $U=0, p<0.01$ for all cases), except for tumor-free mice treated with euflammation ( $p>0.05$ ). Among PBS-treated mice, euflammation influenced hypothalamic Tnfa $\left(F_{1,18}=8.2, p<0.05\right)$, such that euflammation increased Tnfa within tumor-free mice only $\left(t_{9}=2.4, p<0.05\right)$.

Cd11b: $C d 11 b$ is a marker of microglial number/activation and is therefore distinct from the other three proinflammatory cytokine genes. For $C d 11 b$ (Figure 4J-L), both euflammation and LPS treatment independently increased hippocampal Cd11b mRNA $\left(F_{1,36}=21.7\right.$, $\left.p<0.0001 ; F_{1,36}=7.5, p<0.01\right)$. Euflammation increased $C d 11 b$ within both LPS treatments and tumor treatments ( $p<0.05$ in all cases), except this increase did not reach statistical significance for tumor-free LPS-treated mice between euflammation and no euflammation ( $p=0.08$ ). LPS did not statistically significantly increase $C d 11 b$ mRNA among groups within the hippocampus ( $p>0.05$ in all cases). In the hypothalamus, only euflammation treatment significantly altered $C d 11 b\left(F_{1,38}=10.0, p<0.005\right)$, but both the interaction between tumors and LPS and among tumors, euflammation, and LPS treatments approached statistical significance $\left(F_{1,38}=2.6, p=0.1, F_{1,38}=3.6, p=0.06\right)$. Thus, euflammation increased $C d 11 b$ only in the hypothalamus of LPS-treated tumor-bearing mice relative to no euflammation tumor-bearing controls ( $U=4, p<0.05$ ), as well as compared to their tumor-free counterparts $(U=4, p<0.05)$. Euflammation treatment also significantly altered frontal cortex $C d 11 b$ mRNA $\left(F_{1,37}=4.3, p<0.05\right)$, whereas tumor treatment approached statistical significance $\left(F_{1,37}=3.5, p=0.07\right)$. This effects of euflammation on frontal cortex $C d 11 b$ were driven by the PBS-treated controls. Within these controls, euflammation altered $C d 11 b$ gene expression in all three brain regions (hippocampal: $F_{1,18}=11.5, p<0.01$; hypothalamus: $F_{1,19}=5.8, p<0.05$; frontal cortex: $F_{1,19}=5.1, p<0.05$ ), such that euflammation increased hippocampal $C d 11 b$ for both tumor-free and -bearing mice and for tumor-free mice only in the hypothalamus ( $p<0.05$ in all cases). No pairwise differences were found among PBStreated mice for the frontal cortex ( $p>0.05$ in both cases). 
3.4 Behavior-In the spontaneous alternation test, LPS treatment altered total distance traveled (Figure 5A, $F_{1,39}=5.2, p<0.05$ ), such that total distance was reduced in all LPStreated mice relative to their PBS-treated controls (no tumor/no euflamm: $U=8, p=0.1$; no tumor/euflamm: $U=5, p=0.1$; tumor/no euflamm: $t_{10}=2.3, p<0.05$ ), except tumor-bearing mice with euflammation ( $p>0.05)$. Euflammation approached a significant overall effect on distance traveled $\left(F_{1,39}=3.7, p=0.06\right)$, driven by LPS-treated mice, in which euflammation increased total distance traveled in the tumor-bearing mice relative to those without euflammation $\left(t_{10}=2.3, p<0.05\right)$. While no overall effects were statistically significant for the percentage of spontaneous alternations, based on a priori hypotheses, LPS reduced the percentage of spontaneous alternation only in tumor-bearing mice without the euflammation treatment ( $U=6.5, p=0.06$ ). For all other groups, spontaneous alternation remained unperturbed by LPS treatment relative to their respective PBS-treated controls $(p>0.05$ in all cases).

In the novel object recognition test, all treatment groups spent more time investigating the novel object, but no differences in the discrimination index (investigation of novel versus familiar object) were observed among groups (Supplementary Figure 1; $p>0.05$ in all cases). However, LPS and the interaction between LPS and euflammation were significant for the time spent investigating the novel $\left(F_{1,37}=6.7, p<0.05 ; F_{1,37}-10.9, p<0.005\right)$ and familiar objects $\left(F_{1,37}=9.5, p<0.005 ; F_{1,37}=5.1, p<0.05\right)$. This LPS-induced decrease in investigation was not specific to either object (i.e., independent of cognition) and is summarized by the time spent not investigating either object in which both LPS (Figure 5B, $F_{1,37}=30.8$, $p<0.0001)$ and the interaction between euflammation and LPS treatments $\left(F_{1,37}=23.2\right.$, $p<0.0001)$ were significant. Thus, LPS increased time spent not investigating either object in the no euflammation groups only (no tumor: $t_{8}=4.9, p<0.005$; tumor: $t_{9}=6.8, p<0.0001$ ), whereas euflammation protected mice from this reduction in general investigation behavior.

LPS influenced hippocampal $B d n f$ mRNA (Figure 5C; $F_{1,36}=6.1, p<0.05$ ), such that $B d n f$ was reduced by LPS in tumor-free controls without euflammation, whereas this reduction was prevented by the euflammation protocol ( $p>0.05$ ). In contrast, the protective effects of euflammation on LPS-induced reductions in $B d n f$ tended to be absent in tumor-bearing mice $\left(t_{10}=2.1, p=0.06\right)$.

\section{Experiment 2: Effects of euflammation on tumors}

3.5-Completion of the euflammation protocol prior to tumor induction did not alter final tumor mass (data not shown) nor tumor growth (Supplementary Figure 2A; $p>0.05$ for both). The subsequent immune challenge (LPS) occurred $23 \mathrm{~d}$ later in this Experiment and neither tumor nor euflammation treatments influenced neuroinflammation $(\mathrm{p}>0.05$ in all cases). Only LPS significantly increased $I 11 \beta, I l 6$, and Tnfa in all groups (e.g., hippocampal $I I 1 \beta$; Supplementary Figure $\left.2 \mathrm{~B} ; F_{1,23}=40.9, p<0.0001\right)$.

\section{DISCUSSION}

This project was designed to be the first application of an established euflammatory protocol to a chronic disease model (i.e., cancer). In Experiment 1, euflammation dramatically attenuated LPS-induced inflammatory responses in the control $\mathrm{C} 3 \mathrm{H}$ strain of mice, similar to 
that reported previously in FVB mice only [2,3]. Furthermore, euflammation was comparably effective, with respect to peripheral circulating inflammatory responses, even in the presence of a peripheral tumor. Like most solid peripheral tumors, these oral carcinomas are a continuous source of inflammatory signals and immune cells in situ $[35,36]$. In spite of this additional burden on the immune system, conditioning of the peripheral innate immune system by the euflammation protocol successfully resulted in temporal dynamics of peripheral cytokine responses comparable to mice without tumors. Of note, the magnitude of peripheral cytokine responses tended to be higher among tumor-bearing mice for three out of four cytokines examined, however, not to a statistically significant degree. Additionally, these tumors were not metabolically taxing enough to alter body weight [26], nor did euflammation treatment alter final tumor mass. Euflammation slightly attenuated weight gain, although euflammation- and LPS-induced splenomegaly [3,37] remained similar between tumor-bearing and -free mice.

In terms of brain inflammatory responses to LPS, tumors modestly altered the consequences of euflammation treatment. In general, euflammation reduced central inflammatory responses to LPS as predicted [2], but these reductions failed to return to control-like levels for several markers in the tumor-bearing mice only (hypothalamic III , and Tnfa in all 3 brain regions examined). These data suggest that the modulating effects of tumors on euflammation-induced neuroinflammation may be cytokine-specific (i.e., $I 11 \beta$ and $T n f a$, but not Il6). Notably, neuroinflammatory changes driven by tumors did not stem from direct comparisons to tumor-free controls, but rather in that tumor-bearing mice treated with LPS differed from tumor-bearing PBS-treated controls, whereas the equivalent tumor-free groups remained comparable. This suggests that tumors either attenuate or delay euflammationinduced reductions in neuroinflammatory activation. Thus, euflammation was less effective in attenuating LPS-induced neuroinflammatory responses in tumor-bearing mice compared with tumor-free mice.

Using the non-specific myeloid cell surface marker, $C d 11 b$, to assess microglial status in the brain, both euflammation and LPS increased $C d 11 b$ mRNA in the hippocampus in the present study. Given that another microglia marker, Iba1, is reduced in brains of euflammation-treated mice in previous study [2], $C d 11 b$ may reflect the potential migration of peripheral myeloid cells, simply the upregulation of that particular adhesion marker on microglia, or a mouse strain difference. Other brain regions tested did not show this stepwise $C d 11 b$ gene expression response to treatments. While the likelihood that residual circulating immune cells significantly influenced the observed brain neuroinflammatory gene expression is low [38], this possibility remains.

These oral tumors in the flank affected neither resting neuroinflammation nor LPS-induced inflammation in the absence of euflammation. Other peripheral tumors increase resting neuroinflammatory signals $[39,40]$ and a rat model of breast cancer is characterized by exaggerated neuroinflammatory responses to a peripheral LPS injection relative to tumorfree controls [22]. Larger tumor masses may be necessary for these increases in resting and triggered neuroinflammatory signals, as a positive association between tumor mass and neuroinflammation has been observed [22]. 
Euflammation was protective against sickness behavior (locomotor activity) in both tumorbearing and -free mice as exemplified by their post-LPS disinterest in either object during the novel object test. Alternatively, euflammation appeared to be more protective in the tumor-bearing mice for locomotor activity (total distance traveled) after LPS in the Y-maze task relative to tumor-free mice and euflammation-free tumor-bearing mice. Of note, LPS only significantly reduced locomotion in the tumor-bearing mice in this test, indirectly suggesting that tumors may augment LPS-induced lethargy relative to tumor-free controls. Indeed, tumors increased anorexic sickness responses to LPS in rats [17].

Acute cognitive impairments after LPS treatment have not been as extensively investigated as sickness behaviors and had not yet been studied in the context of euflammation. From the existing literature, studies report LPS-induced disruptions in spatial learning in a water maze, novel object recognition, and spontaneous alternation $6 \mathrm{~h}-7 \mathrm{~d}$ after a single high dose of LPS (600-800 $\mu \mathrm{g} / \mathrm{kg}$ ) [30,31], impairment of active avoidance after a common dose of LPS $(250 \mu \mathrm{g} / \mathrm{kg})$ [32], and impairment of contextual conditioning in rats [44]. These LPSinduced cognitive impairments appear to be driven by IL-1 $\beta[44,45]$. In the present study, the $250 \mu \mathrm{g} / \mathrm{kg}$ dose LPS drove mild cognitive impairments in spontaneous alternation approximately $1.5-2 \mathrm{~h}$ post-injection in the tumor-bearing mice only, which was rescued by euflammation. This cognitive effect is not confounded by potential differences in lethargy as overall locomotion is controlled for in its calculation (percent not absolute alternations). However, euflammation did not rescue associated LPS-induced decreases in hippocampal $B d n f$ in the tumor-bearing mice. Therefore, the protective effects of euflammation on tumorinduced cognitive responses to LPS were independent of hippocampal $B d n f$ and, potentially, neurogenesis mechanisms. BDNF is important for survival and growth of neurons and its expression is correlated with learning. Effects of acute LPS on BDNF are mixed [46-48]. Indeed, other LPS and cognition studies have shown a discordance between hippocampal BDNF and learning [37]. Finally, cognitive changes in hippocampal-independent learning and memory based on tumors, euflammation, or LPS were absent in the novel object recognition task. This indicates that different types of cognitive function may vary in their susceptibility to being modulated by these factors. Taken together, these data suggest a preliminary interaction between tumors and LPS treatment on behavior. Thus, euflammation might recover behavioral differences observed in response to euflammation that are unmasked by a tumor. Indeed, behavioral deficits in cancer patients are often only unmasked after a physiological challenge. Given the low sample size $(n=6)$ in the present behavioral investigation, further replication of these findings are necessary.

Finally, the hypothesis that euflammation may reduce tumor initiation, growth, or later responses to an immune challenge was assessed in Experiment 2. Indeed, the anti-tumor activity of repeated LPS or other bacterial toxins was initially reported in the $19^{\text {th }}$ century $[5,49]$. Therefore, the present rationale was that tumor initiation may be reduced by euflammation-induced reductions in local inflammatory responses, as local inflammation can drive tumorigenesis of oral and many other cancers [50,51]. However, in Experiment 2, no differences in tumor incidence $(100 \%)$ or tumor growth rates were observed. Indeed, without a recent immune stimulus (e.g., LPS), local resting inflammation would likely not differ between mice treated with the euflammatory protocol and those without. Additionally, suppression of inflammation with the euflammatory protocol had only been investigated 
when the immune challenge (LPS) occurred immediately after euflammation. In Experiment 2 , the immune challenge was delayed almost 3 weeks after the euflammatory protocol and resulted in no attenuation of LPS-induced neuroinflammation. Therefore, the functional duration of reducing neuroinflammation using this 3-day euflammatory protocol is finite. Furthermore, while inflammatory responses to immune challenges are attenuated after euflammation, peripheral macrophage function and number are enhanced [3], resembling a more efficient macrophage response. While a potentially similar macrophage change may occur when euflammation is applied to a tumor model, it does not appear to alter tumor growth. However, peripheral macrophage efficiency may be relevant to other concurrent cancer-related immune functions (e.g., healing post-surgery).

In summary, this research sought to apply a recently established euflammatory protocol, which modifies subsequent brain and behavioral responses in the absence of illness side effects, to the promising field of anti-cancer bacterial treatment, which is currently constrained by these negative side effects. Furthermore, while repeated exposure to bacterial toxins can successful inhibit tumor biology, it had not been examined as a potential modifier of inflammation-induced behavioral changes reported in cancer populations. Here, we demonstrate that euflammation ameliorates neuroinflammatory signaling and select cognitive deficits unmasked by the presence of a tumor. Based on these results using an established E. coli-based euflammatory protocol, the potential development of a euflammatory protocol using other bacteria that are used clinically to reduce tumors (e.g., Salmonella, Clostridium) is warranted. The potential prophylactic application of a subsymptomatic euflammatory protocol in susceptible populations may have the potential to prevent or attenuate debilitating behavioral comorbidities in addition to its anti-tumor applications.

\section{Supplementary Material}

Refer to Web version on PubMed Central for supplementary material.

\section{Acknowledgments}

The authors thank Hsin-Yun Lin, Daniel Nemeth, Lindsay Strehle, Browning Haynes, Joshua Bellisario, Jasskiran Kaur, Trina Wemlinger, and Shireen Desai for technical assistance and Pete McKinley for animal care. This work was supported by the Ohio State University Medical Center, an NIH grant CA201681, and a CCTS core grant UL1TR001070 (L.P)

\section{References}

1. Dantzer R, O'Connor JC, Freund GG, Johnson RW, Kelley KW. From inflammation to sickness and depression: when the immune system subjugates the brain. Nat Rev Neurosci. 2008; 9:46-56. [PubMed: 18073775]

2. Liu X, Nemeth DP, Tarr AJ, Belevych N, Syed ZW, Wang Y, Ismail AS, Reed NS, Sheridan JF, Yajnik AR, Disabato DJ, Zhu L, Quan N. Euflammation attenuates peripheral inflammation-induced neuroinflammation and mitigates immune-to-brain signaling. Brain Behav Immun. 2016; 54:140 148. [PubMed: 26812118]

3. Tarr AJ, Liu X, Reed NS, Quan N. Kinetic characteristics of euflammation: the induction of controlled inflammation without overt sickness behavior. Brain Behav Immun. 2014; 42:96-108. [PubMed: 24929192] 
4. Okassov A, Nersesyan A, Kitada S, Ilin A. Parasporins as new natural anticancer agents: a review. Journal of BUON: official journal of the Balkan Union of Oncology. 2015; 20:5-16.

5. Katano M, Morisaki T. The past, the present and future of the OK-432 therapy for patients with malignant effusions. Anticancer Res. 1998; 18:3917-3925. [PubMed: 9854504]

6. Qian C, Feng P, Yu J, Chen Y, Hu Q, Sun W, Xiao X, Hu X, Bellotti A, Shen QD, Gu Z. AnaerobeInspired Anticancer Nanovesicles. Angew Chem Int Ed Engl. 2017; 56:2588-2593. [PubMed: 28140504]

7. Liu S, Xu X, Zeng X, Li L, Chen Q, Li J. Tumor-targeting bacterial therapy: A potential treatment for oral cancer (Review). Oncol Lett. 2014; 8:2359-2366. [PubMed: 25364397]

8. Huang GT, Yang PM, Sheu JC, Hsu HC, Sung JL, Wang TH, Chen DS. Intratumor injection of OK-432 for the treatment of small hepatocellular carcinoma. Hepatogastroenterology. 1990; 37:452-456. [PubMed: 2174823]

9. Wefel JS, Kesler SR, Noll KR, Schagen SB. Clinical characteristics, pathophysiology, and management of noncentral nervous system cancer-related cognitive impairment in adults. CA Cancer J Clin. 2015; 65:123-138. [PubMed: 25483452]

10. Koppelmans V, Breteler MM, Boogerd W, Seynaeve C, Gundy C, Schagen SB. Neuropsychological performance in survivors of breast cancer more than 20 years after adjuvant chemotherapy. J Clin Oncol. 2012; 30:1080-1086. [PubMed: 22370315]

11. Hess LM, Insel KC. Chemotherapy-related change in cognitive function: a conceptual model. Oncol Nurs Forum. 2007; 34:981-994. [PubMed: 17878127]

12. Jagsi R, Hawley ST, Abrahamse P, Li Y, Janz NK, Griggs JJ, Bradley C, Graff JJ, Hamilton A, Katz SJ. Impact of adjuvant chemotherapy on long-term employment of survivors of early-stage breast cancer. Cancer. 2014; 120:1854-1862. [PubMed: 24777606]

13. Dantzer R, Meagher MW, Cleeland CS. Translational approaches to treatment-induced symptoms in cancer patients. Nature reviews Clinical oncology. 2012; 9:414-426.

14. Schrepf A, Lutgendorf SK, Pyter LM. Pre-treatment effects of peripheral tumors on brain and behavior: neuroinflammatory mechanisms in humans and rodents. Brain Behav Immun. 2015; 49:1-17. [PubMed: 25958011]

15. Ichikura K, Yamashita A, Sugimoto T, Kishimoto S, Matsushima E. Persistence of psychological distress and correlated factors among patients with head and neck cancer. Palliative \& supportive care. 2016; 14:42-51. [PubMed: 26089108]

16. Welsh LC, Dunlop AW, McGovern T, McQuaid D, Dean JA, Gulliford SL, Bhide SA, Harrington KJ, Nutting CM, Newbold KL. Neurocognitive function after (chemo)-radiotherapy for head and neck cancer. Clin Oncol (R Coll Radiol). 2014; 26:765-775. [PubMed: 25028338]

17. Bond SM, Dietrich MS, Murphy BA. Neurocognitive function in head and neck cancer patients prior to treatment. Support Care Cancer. 2012; 20:149-157. [PubMed: 21229270]

18. Andreano JM, Waisman J, Donley L, Cahill L. Effects of breast cancer treatment on the hormonal and cognitive consequences of acute stress. Psychooncology. 2012; 21:1091-1098. [PubMed: 21874658]

19. Maruna P, Gurlich R, Rosicka M. Ghrelin as an acute-phase reactant during postoperative stress response. Horm Metab Res. 2008; 40:404-409. [PubMed: 18404598]

20. Pyter LM, Cochrane SF, Ouwenga RL, Patel PN, Pineros V, Prendergast BJ. Mammary tumors induce select cognitive impairments. Brain Behav Immun. 2010; 24:903-907. [PubMed: 20188817]

21. Yang M, Kim J, Kim JS, Kim SH, Kim JC, Kang MJ, Jung U, Shin T, Wang H, Moon C. Hippocampal dysfunctions in tumor-bearing mice. Brain Behav Immun. 2014; 36:147-155. [PubMed: 24513875]

22. Pyter LM, El Mouatassim Bih S, Sattar H, Prendergast BJ. Peripheral tumors alter neuroinflammatory responses to lipopolysaccharide in female rats. Brain Res. 2014; 1552:55-63. [PubMed: 24457042]

23. Calabrese F, Rossetti AC, Racagni G, Gass P, Riva MA, Molteni R. Brain-derived neurotrophic factor: a bridge between inflammation and neuroplasticity. Frontiers in cellular neuroscience. 2014; 8:430. [PubMed: 25565964] 
24. Sultzer BM. Genetic control of leucocyte responses to endotoxin. Nature. 1968; 219:1253-1254. [PubMed: 4877918]

25. Council, NR., editor. NRC. Guide for the care and use of laboratory animals. Washington DC: The National Academies Press; 2011.

26. Pyter LM, Husain Y, Calero H, McKim DB, Lin HY, Godbout JP, Sheridan JF, Engeland CG, Marucha PT. Tumors Alter Inflammation and Impair Dermal Wound Healing in Female Mice. PloS one. 2016; 11:e0161537. [PubMed: 27548621]

27. Lou E, Kellman RM, Hutchison R, Shillitoe EJ. Clinical and pathological features of the murine AT-84 orthotopic model of oral cancer. Oral Dis. 2003; 9:305-312. [PubMed: 14629332]

28. Vahle AK, Kerem A, Ozturk E, Bankfalvi A, Lang S, Brandau S. Optimization of an orthotopic murine model of head and neck squamous cell carcinoma in fully immunocompetent mice-role of toll-like-receptor 4 expressed on host cells. Cancer Lett. 2012; 317:199-206. [PubMed: 22123294]

29. Lalonde R. The neurobiological basis of spontaneous alternation. Neurosci Biobehav Rev. 2002; 26:91-104. [PubMed: 11835987]

30. Tam SK, Hasan S, Hughes S, Hankins MW, Foster RG, Bannerman DM, Peirson SN. Modulation of recognition memory performance by light requires both melanopsin and classical photoreceptors. Proc Biol Sci. 2016; 283

31. Katzav A, Arango MT, Kivity S, Tanaka S, Givaty G, Agmon-Levin N, Honda M, Anaya JM, Chapman J, Shoenfeld Y. Passive transfer of narcolepsy: anti-TRIB2 autoantibody positive patient IgG causes hypothalamic orexin neuron loss and sleep attacks in mice. J Autoimmun. 2013; 45:24-30. [PubMed: 23834844]

32. Win-Shwe TT, Nakajima D, Ahmed S, Fujimaki H. Impairment of novel object recognition in adulthood after neonatal exposure to diazinon. Arch Toxicol. 2013; 87:753-762. [PubMed: 23212306]

33. Kim YK, Na KS, Myint AM, Leonard BE. The role of pro-inflammatory cytokines in neuroinflammation, neurogenesis and the neuroendocrine system in major depression. Prog Neuropsychopharmacol Biol Psychiatry. 2016; 64:277-284. [PubMed: 26111720]

34. Tyler WJ, Alonso M, Bramham CR, Pozzo-Miller LD. From acquisition to consolidation: on the role of brain-derived neurotrophic factor signaling in hippocampal-dependent learning. Learn Mem. 2002; 9:224-237. [PubMed: 12359832]

35. Candido J, Hagemann T. Cancer-related inflammation. J Clin Immunol. 2013; 33(Suppl 1):S79-84. [PubMed: 23225204]

36. Pyter LM, McKim DB, Husain Y, Calero H, Godbout JP, Sheridan JF, Marucha PT, Engeland CG. Effects of dermal wounding on distal primary tumor immunobiology in female mice. in review.

37. Liverani E, Rico MC, Yaratha L, Tsygankov AY, Kilpatrick LE, Kunapuli SP. LPS-induced systemic inflammation is more severe in P2Y12 null mice. J Leukoc Biol. 2014; 95:313-323. [PubMed: 24142066]

38. Wohleb ES, Hanke ML, Corona AW, Powell ND, Stiner LM, Bailey MT, Nelson RJ, Godbout JP, Sheridan JF. beta-Adrenergic receptor antagonism prevents anxiety-like behavior and microglial reactivity induced by repeated social defeat. J Neurosci. 2011; 31:6277-6288. [PubMed: 21525267]

39. Norden DM, Bicer S, Clark Y, Jing R, Henry CJ, Wold LE, Reiser PJ, Godbout JP, McCarthy DO. Tumor growth increases neuroinflammation, fatigue and depressive-like behavior prior to alterations in muscle function. Brain Behav Immun. 2015; 43:76-85. [PubMed: 25102452]

40. Pyter LM, Pineros V, Galang JA, McClintock MK, Prendergast BJ. Peripheral tumors induce depressive-like behaviors and cytokine production and alter hypothalamic-pituitary-adrenal axis regulation. Proc Natl Acad Sci U S A. 2009; 106:9069-9074. [PubMed: 19451634]

41. Arai K, Matsuki N, Ikegaya Y, Nishiyama N. Deterioration of spatial learning performances in lipopolysaccharide-treated mice. Jpn J Pharmacol. 2001; 87:195-201. [PubMed: 11885968]

42. El-Sayed NS, Bayan Y. Possible role of resveratrol targeting estradiol and neprilysin pathways in lipopolysaccharide model of Alzheimer disease. Adv Exp Med Biol. 2015; 822:107-118. [PubMed: 25416980] 
43. Sparkman NL, Kohman RA, Garcia AK, Boehm GW. Peripheral lipopolysaccharide administration impairs two-way active avoidance conditioning in C57BL/6J mice. Physiol Behav. 2005; 85:278288. [PubMed: 15936787]

44. Pugh CR, Kumagawa K, Fleshner M, Watkins LR, Maier SF, Rudy JW. Selective effects of peripheral lipopolysaccharide administration on contextual and auditory-cue fear conditioning. Brain Behav Immun. 1998; 12:212-229. [PubMed: 9769157]

45. Oitzl MS, van Oers H, Schobitz B, de Kloet ER. Interleukin-1 beta, but not interleukin-6, impairs spatial navigation learning. Brain Res. 1993; 613:160-163. [PubMed: 8348300]

46. Elkabes S, Peng L, Black IB. Lipopolysaccharide differentially regulates microglial trk receptor and neurotrophin expression. J Neurosci Res. 1998; 54:117-122. [PubMed: 9778155]

47. Miwa T, Furukawa S, Nakajima K, Furukawa Y, Kohsaka S. Lipopolysaccharide enhances synthesis of brain-derived neurotrophic factor in cultured rat microglia. J Neurosci Res. 1997; 50:1023-1029. [PubMed: 9452017]

48. Shaw KN, Commins S, O'Mara SM. Lipopolysaccharide causes deficits in spatial learning in the watermaze but not in BDNF expression in the rat dentate gyrus. Behav Brain Res. 2001; 124:4754. [PubMed: 11423165]

49. Rakoff-Nahoum S, Medzhitov R. Toll-like receptors and cancer. Nature reviews Cancer. 2009; 9:57-63. [PubMed: 19052556]

50. Peek RM Jr, Mohla S, DuBois RN. Inflammation in the genesis and perpetuation of cancer: summary and recommendations from a national cancer institute-sponsored meeting. Cancer Res. 2005; 65:8583-8586. [PubMed: 16204020]

51. Sarode GS, Sarode SC, Patil A, Anand R, Patil SG, Rao RS, Augustine D. Inflammation and Oral Cancer: An Update Review on Targeted Therapies. J Contemp Dent Pract. 2015; 16:595-602. [PubMed: 26329416] 


\section{A)}

\section{EXPERIMENT 1}

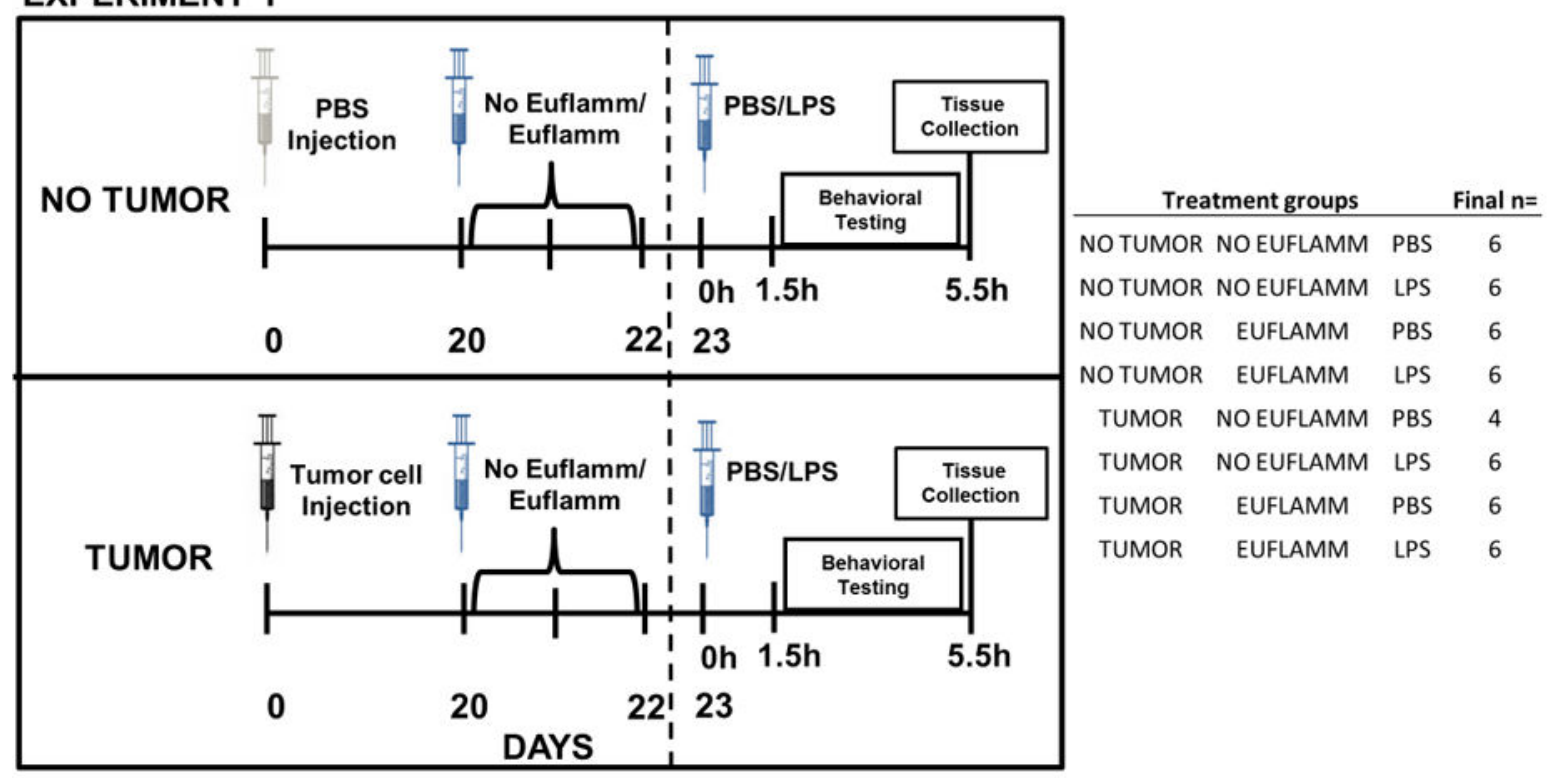

B)

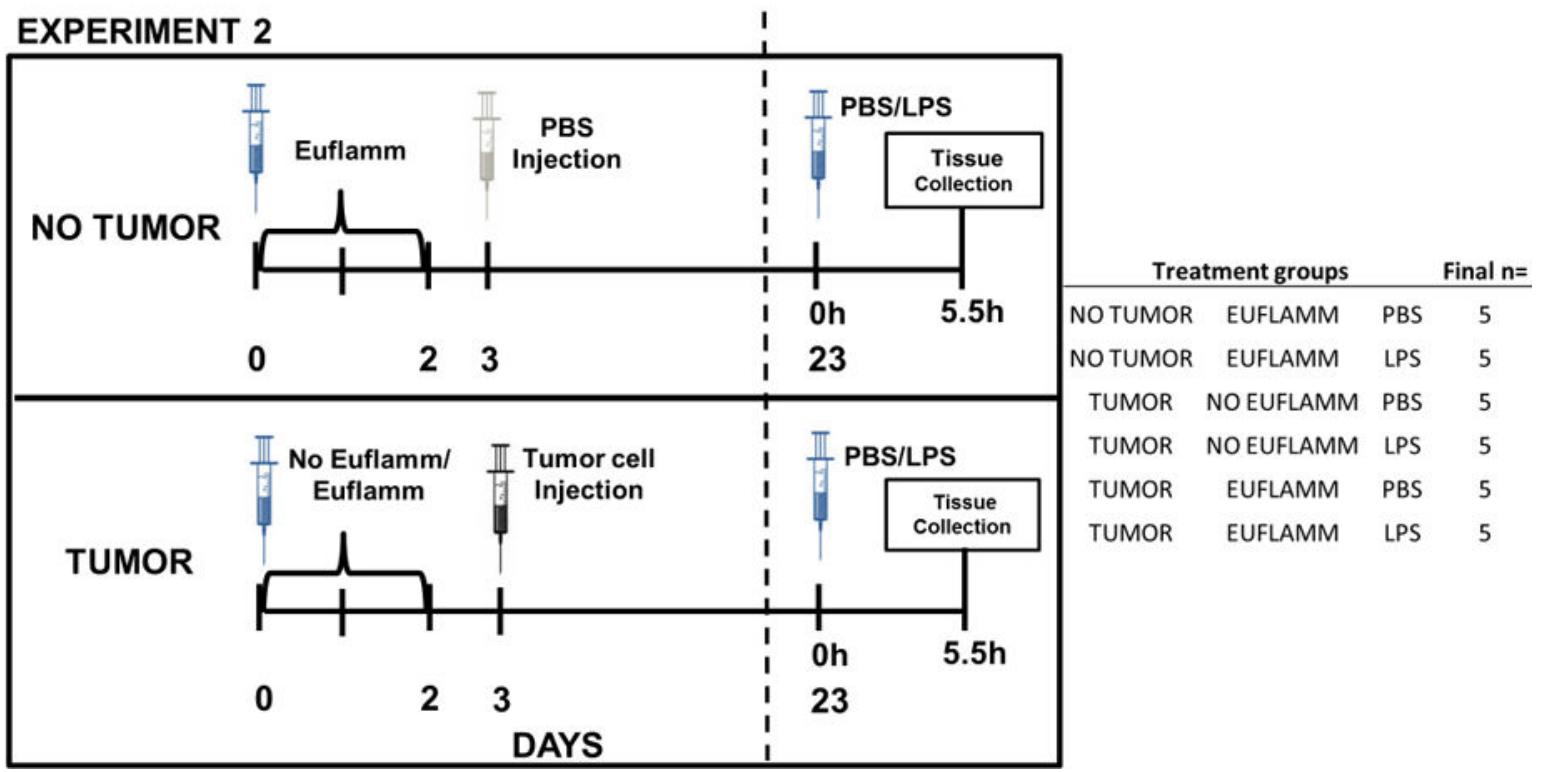

Figure 1. Experimental timelines and samples sizes

A) Experiment 1 and B) Experiment 2 temporal sequence of treatments, behavior, and tissue collection and associated group sample sizes. 
A)

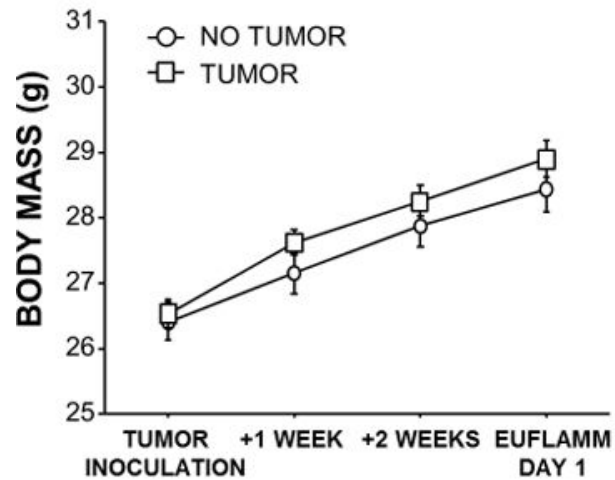

B)

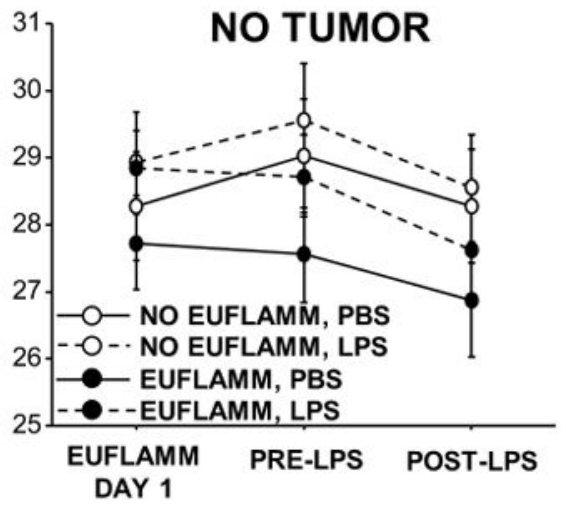

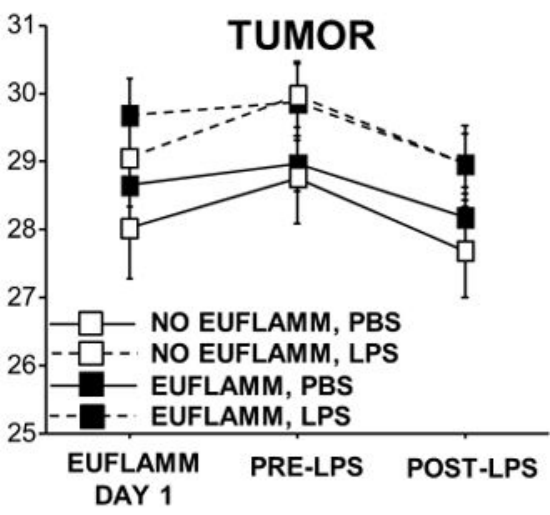
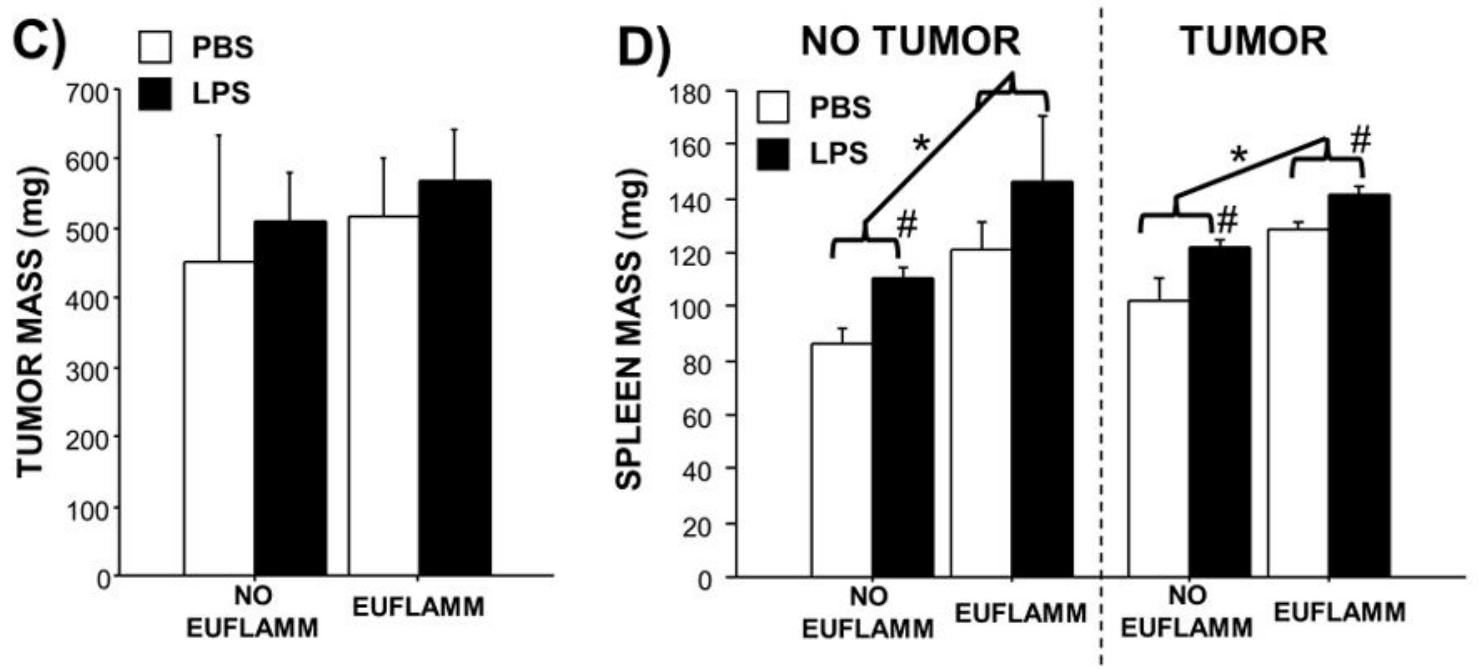

Figure 2. Effects of tumors on euflammation-induced changes in tissue masses after acute immune stimulation in Experiment 1

Mean \pm SEM body mass A) after tumor inoculation and before euflammation treatment and B) after euflammation in tumor-bearing versus tumor-free mice. Mean \pm SEM C) tumor mass and D) spleen mass among treatment groups. ${ }^{*} \mathrm{p}<0.05$ between euflammation and no euflammation; ${ }^{\#}$ p $<0.05$ between LPS $(250 \mu \mathrm{g} / \mathrm{ml}$, i.p. $)$ and PBS challenges 

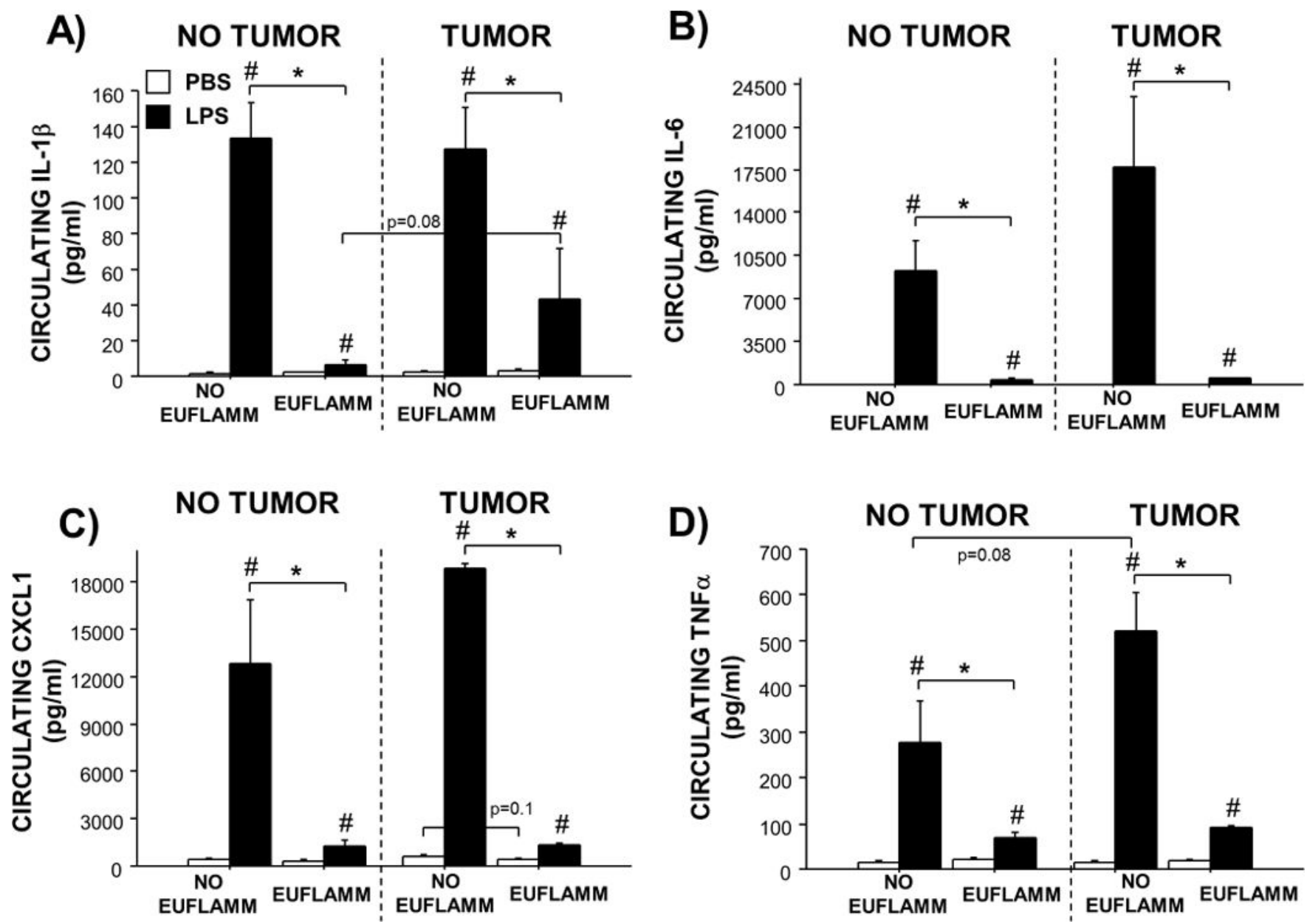

Figure 3. Effects of tumors on euflammation-induced changes in circulating cytokine concentrations after acute immune stimulation in Experiment 1

Mean \pm SEM circulating A) IL-1 $\beta$, B) IL-6, C) CXCL1, and D) TNFa concentrations in responses to LPS or PBS challenges (5.5 h prior) among tumor and euflammation treatments. ${ }^{*} \mathrm{p}<0.05$ between euflammation and no euflammation; ${ }^{*} \mathrm{p}<0.05$ between LPS and PBS challenges 

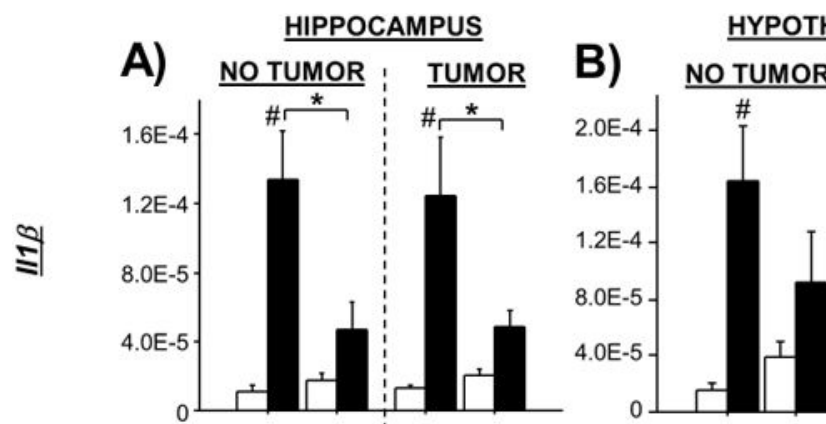

FRONTAL CORTEX
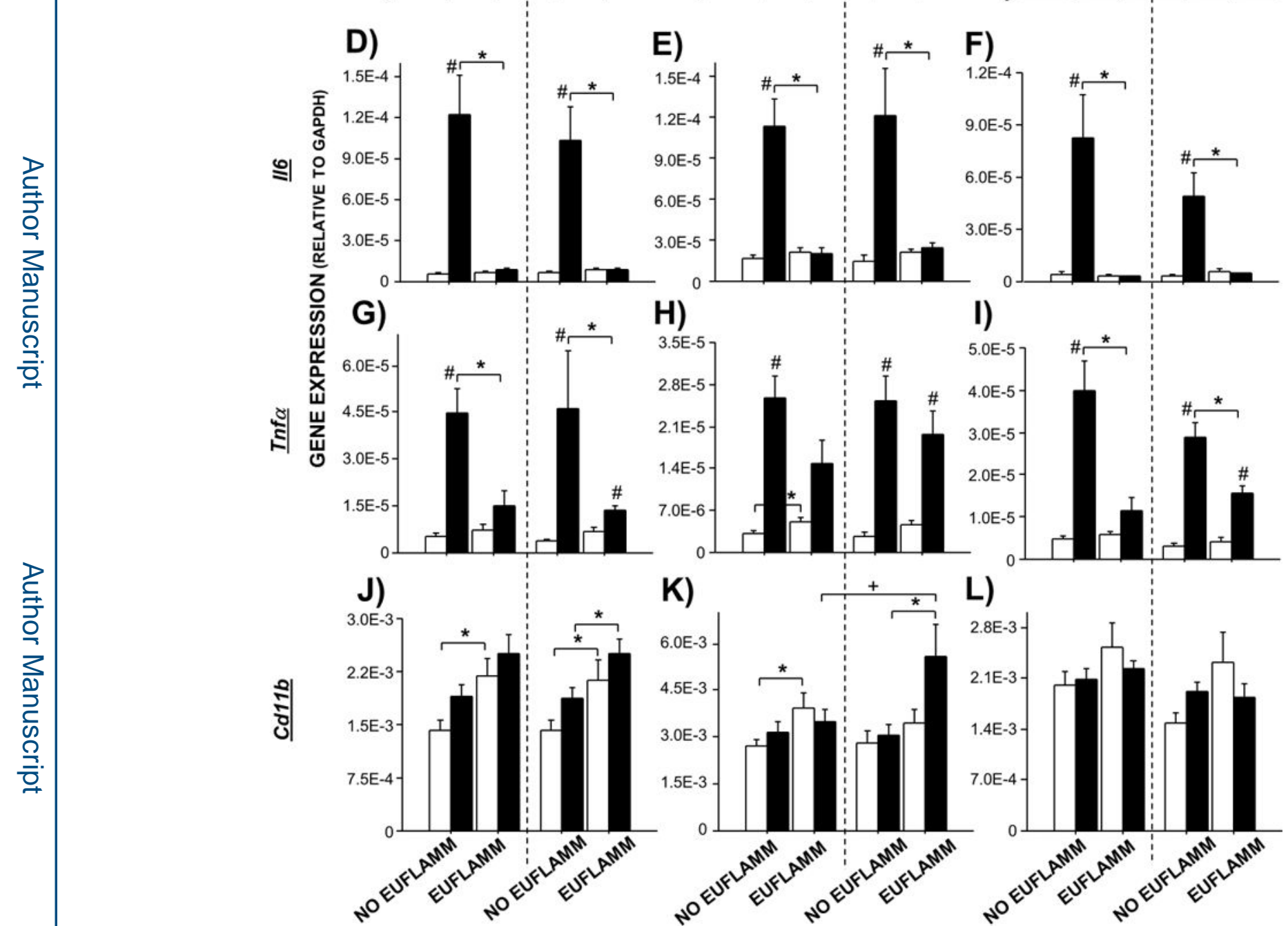

Figure 4. Effects of tumors on euflammation-induced changes in neuroinflammation marker gene expression after acute immune stimulation in Experiment 1

Mean \pm SEM quantitative A-C) $I 11 \beta$, D-F) $I 16$, G-I) Tnfa, and J-L) $C d 11 b$ mRNA expression after LPS or PBS challenges (5.5 h prior) among tumor and euflammation treatments. ${ }^{*} \mathrm{p}<0.05$ between euflammation and no euflammation; ${ }^{*} \mathrm{p}<0.05$ between LPS and PBS challenges; ${ }^{+} \mathrm{p}<0.05$ between tumor and no tumor 
A) SPONTANEOUS ALTERNATION
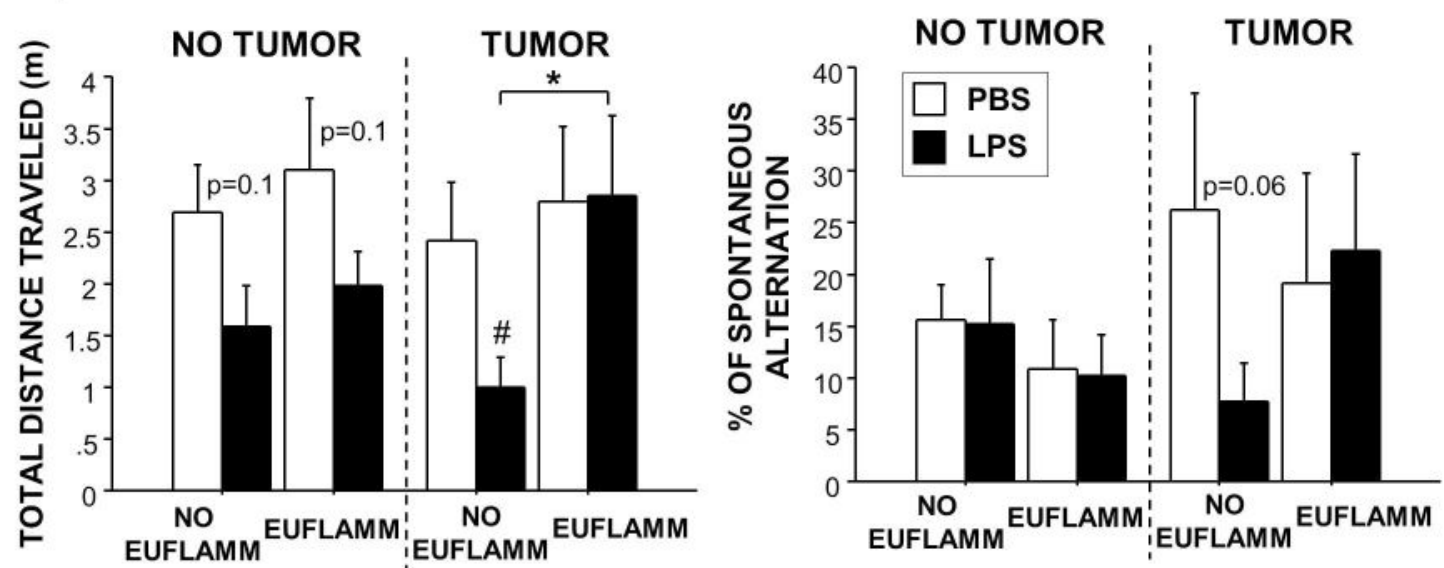

B) NOVEL OBJECT RECOGNITION

C) HIPPOCAMPAL Bdnf MRNA
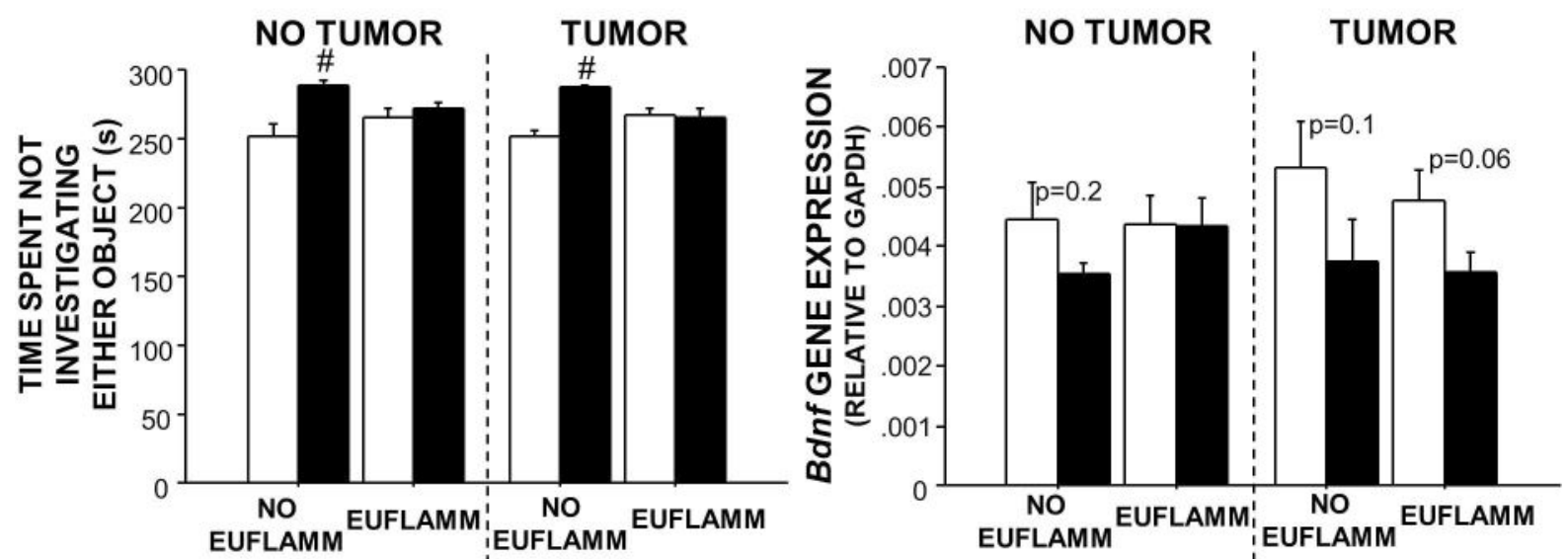

Figure 5. Effects of tumors on euflammation-induced changes in behavior and related hippocampal gene expression after acute immune stimulation in Experiment 1

A) Mean \pm SEM locomotion behavior and working spatial memory behavior in the spontaneous alternation Y-maze test $1.5 \mathrm{~h}$ after LPS or PBS challenge. B) Mean \pm SEM locomotion behavior in the novel object recognition task $4 \mathrm{~h}$ after LPS or PBS challenge. C) Mean \pm SEM quantitative gene expression of brain-derived growth factor in the hippocampus of tumor and/or euflammation-treated mice $5.5 \mathrm{~h}$ post LPS or PBS challenge. ${ }^{*} \mathrm{p}<0.05$ between euflammation and no euflammation; ${ }^{*} \mathrm{p}<0.05$ between LPS and PBS challenges 